\title{
AKTIVITAS ANTIOKSIDAN EKSTRAK KULIT BATANG KERSEN \\ (Muntingia calabura L.)
}

\author{
Fathiah Olpah Siara, Arsyik Ibrahim, Hanggara Arifian, Rolan Rusli* \\ Laboratorium Penelitian dan Pengembangan FARMAKA TROPIS, Fakultas \\ Farmasi Universitas Mulawarman, Samarinda, Kalimantan Timur \\ *Email: rolan@farmasi.unmul.ac.id
}

\begin{abstract}
ABSTRAK
Seduhan kulit batang Tumbuhan Kersen (Muntingia calabura L.) sering digunakan sebagai obat tradisional. Hasil Skrining fitokimia ekstrak dan fraksi kulit batang kersen menunjukkan Adanya kandungan alkaloid, flavonoid, tannin, saponin dan terpenoid. Nilai $\mathrm{IC}_{50}$ ekstrak dan fraksi kulit batang kersen dengan menggunakan metode DPPH untuk ekstrak etanol, fraksi $n$-heksana, fraksi etil asetat, dan fraksi tidak larut dari kulit batang Tumbuhan Kersen berturut-turut adalah sebesar 19,63 ppm, 34,38 ppm, 10,65 ppm, dan $18,70 \mathrm{ppm}$, sedangkan $\mathrm{IC}_{50}$ kontrol positif (vitamin C) adalah 14,77 ppm. Ekstrak kulit batang kersen berpotensi sebagai antioksidan.
\end{abstract}

Kata Kunci: Antioksidan, Metabolit Sekunder, Vitamin C, DPPH, IC50

\begin{abstract}
Kersen plant bark (Muntingia calabura L.) is often used as a traditional medicine. Result Screening of phytochemical of Muntingia calbura L. extract were alkaloid, flavonoid, tannin, saponin and terpenoid. Values of IC 50 Muntingia calabura L. using DPPH method for ethanol extract, $n$-hexane fraction, ethyl acetate fraction and insoluble fraction respectively were $19.63 \mathrm{ppm}, 34.38 \mathrm{ppm}, 10.65 \mathrm{ppm}$, and 18.70 ppm. Whilst, IC50 values of positive control (Vitamin C) was $14.77 \mathrm{ppm}$. Extract of Muntingia calabura L. bark has potential as an antioxidant.
\end{abstract}

Keywords: Antioxidant, Secondary metabolites, Vitamin C, DPPH, IC50

\section{PENDAHULUAN}

Seduhan kulit batang Tumbuhan Kersen (Muntingia calabura L.) sering digunakan sebagai obat tradisional. Kersen (Muntingia calabura L.) secara ilmiah memiliki jenis flavonoid dan flavon telah diisolasi dan diidentifikasi dari Muntingia calabura L. Tanaman ini mengandung banyak flavonoid pada bagian daunnya 
(Manik, 2014). Akan tetapi belum ada laporan mengenai uji aktivitas antioksidan dari kulit batang kersen.

Penelitian ini untuk mengetahui aktivitas antioksidan ekstrak kasar, fraksi $n$-heksana, fraksi etil asetat, dan fraksi tidak larut kulit batang kersen (Muntingia calabura L.) untuk dapat dikembangkan dan diketahui khasiat dan potensinya yang menunjang untuk penelitian sebelumnya untuk mengembangkan khasiat dari kersen.

\section{METODE PENELITIAN}

\section{Alat dan Bahan}

Alat yang digunakan pada penelitian ini adalah Batang pengaduk, cawan porselin, corong kaca, corong pisah, corong porselin, gelas kimia, gelas ukur, hot plate, kaca arloji, kuvet, labu ukur, mangkok kaca, penjepit tabung, pipet tetes, pipet ukur, pisau, pro pipet, rak tabung, rotary evaporator, spektofotometer, statif dan klem, tabung reaksi, timbangan analitik, toples kaca, vortex. Bahan yang digunakan adalah Aquades, DPPH, Etil Aseat, Etanol, n-heksana, Simplisia Kulit Batang Kersen, Vitamin C, HCl, Preaksi Dragendroff, Preaksi Mayer, Logam Magnesium, $\mathrm{FeCl}_{3}$, Asam sulfat pekat, dan Asam asetat anhidrat

\section{Prosedur Kerja}

Penelitian ini menggunakan sampel ekstrak dan fraksi kulit batang kersen. Cara ekstraksi dengan metode maserasi dan fraksinasi cair-cair untuk selanjutnya diuji aktivitas antioksidan. Kulit batang kersen diperoleh dari Samarinda, Kalimantan timur. Ekstrak yang diuji adalah ekstrak etanol sedangkan untuk fraksi yang akan diuji adalah fraksi $n$-heksana, fraksi etil asetat dan fraksi tidak larut.

Aktivitas antioksidan dianalisis melalui besarnya peredaman radikal DPPH oleh ekstrak atau fraksi kulit batang kersen terhadap peredaman radikal DPPH. Besarnya peredaman radikal DPPH oleh ekstrak kulit batang kersen dapat diketahui melalui pengukuran absorbansi radikal DPPH menggunakan spektroskopi UV-Vis. Nilai $\mathrm{IC}_{50}$ ekstrak dan fraksi kulit batang kersen menunjukkan sifat antioksidan sangat kuat. 


\section{Pengolahan Ekstrak Kulit Batang Kersen}

Proses ekstraksi dilakukan dengan metode maserasi yaitu kulit batang kersen kering yang telah disortasi dan diangin-anginkan, simplisia kering (1,230 $\mathrm{kg}$ ) yang diperoleh dimasukkan ke dalam toples kaca A, B, dan C, masing-masing sebanyak 500, 500, dan 230 gram. Selanjutnya dilakukan proses ekstraksi menggunakan pelarut etanol. Pelarut etanol dituang secara perlahan-perlahan ke dalam toples kaca yang berisi sampel sambil diaduk hingga homogen. Pelarut etanol dibiarkan sampai $1 \mathrm{~cm}$ diatas permukaan sampel. Ekstaksi dilakukan hingga warna larutan tidak pekat lagi umumnya $3 \times 24$ jam dan setiap 24 jam pelarut etanol diganti sambil sekali-sekali diaduk. Filtrat hasil ekstraksi yang melalui proses penyaringan diuapkan dengan menggunakan rotary evaporation dan di anginanginkan hingga diperoleh ekstrak kental.

\section{Penyiapan fraksi $\boldsymbol{n}$-heksana, etil asetat, dan fraksi etanol.}

Proses fraksinasi ekstrak dilakukan secara bertingkat dengan metode fraksinasi cair-cair. Pada fraksinasi dibuat fraksi ekstrak kulit batang kersen dengan dua macam pelarut yang berbeda sesuai dengan tingkat kepolarannya yaitu dari pelarut dengan kepolaran rendah sampai pelarut dengan kepolaran yang lebih tinggi yaitu $n$-heksana dan kemudian etil asetat. Ekstrak kering kulit batang kersen ditimbang sebanyak 10 gram kemudian dilarutkan dengan aquades.

Selanjutnya ditambahkan pelarut $n$-heksana dan dilakukan penggojogan di dalam corong pisah. Setelah beberapa menit terbentuk dua lapisan. Lapisan bawah diambil untuk dilanjutkan fraksinasi dengan etil asetat, dan sisa dari fraksinasi etil asetat itulah yang disebut fraksi tidak larut. Dalam setiap pelarut organik dilakukan beberapa kali pengulangan hingga lapisan atas terlihat bening. Lapisan atas hasil fraksinasi dikeringkan dengan cara diangin-anginkan (untuk fraksi tidak larut dilarutkan penguapan di atas penangas) sehingga diperoleh ekstrak kental.

\section{Identifikasi Metabolit Sekunder Alkaloid}

Uji golongan alkaloid menggunakan $2 \mathrm{~mL}$ ekstrak dan ditambahkan $2 \mathrm{~mL}$ $\mathrm{HCl} 2 \%$ lalu ditambahkan pereaksi dragendrof (bereaksi positif jika keruh atau endapan jingga) dan pereaksi mayer (bereaksi positif jika terbentuk endapan putih kekuningan). 


\section{Flavonoid}

Uji golongan flavonoid menggunakan $2 \mathrm{~mL}$ ekstrak dan ditambahkan logam magnesium dan 4 tetes $\mathrm{HCl}$ pekat, reaksi positif jika ditandai dengan larutan menjadi warna merah, jingga atau gelap

\section{Fenolik}

Uji golongan fenol menggunakan $2 \mathrm{~mL}$ ekstrak dan ditambahkan 3 tetes $\mathrm{FeCl}_{3}$, reaksi positif ditandai dengan larutan menjadi warna biru atau hitam.

\section{Tanin}

Uji golongan tanin menggunakan 2 mL ekstrak dan ditambahkan 2-3 tetes $\mathrm{FeCl}_{3}$, bereaksi positif jika larutan menjadi warna biru atau hitam

\section{Saponin}

Uji golongan saponin menggunakan $2 \mathrm{~mL}$ eksrak dan dicampurkan air lalu dikocok kuat dan ditambahkan 10 tetes $\mathrm{HCl} 0,1 \mathrm{~N}$, reaksi positif ditandai dengan terbentuknya buih stabil selama 15 menit maka terbukti adanya golongan saponin.

\section{Steroid dan Terpenoid}

Uji golongan steroid dan terpenoid menggunakan $2 \mathrm{~mL}$ ekstrak lalu ditambahkan 3 tetes preaksi asam asetat anhidrat dan 3 tetes asam sulfat pekat (preaksi Liebermann Burchard). Terbentuknya cincin merah menandakan positif untuk senyawa terpenoid dan terbentuknya cincin biru atau hijau menandakan positif untuk steroid.

\section{Pengujian Aktivitas Antioksidan}

Untuk penentuan aktivitas antioksidan ekstrak dan fraksi kulit batang kersen menggunakan metode peredaman radikal bebas DPPH. Kristal DPPH ditimbang sebanyak 4 mg untuk dilarutkan dalam $100 \mathrm{~mL}$ etanol sehingga didapatkan laurutan DPPH dengan konsentrasi sebesar $40 \mathrm{ppm}$. Disimpan larutan DPPH selama 20 menit untuk melindungi dari cahaya. Kemudian, dibuat larutan ekstrak dan fraksi kulit batang kersen menggunakan etanol. Sebanyak $1 \mathrm{~mL}$ larutan ekstrak tersebut ditambahkan dengan $3 \mathrm{~mL}$ larutan DPPH 40 ppm dan dibiarkan selama 20 menit pada temperatur ruang (terhindar dari cahaya). Pengukuran absorban dilakukan pada panjang gelombang $517 \mathrm{~nm}$ Sebagai pembanding digunakan vitamin C. 


\section{HASIL DAN PEMBAHASAN}

Kulit batang kersen (Muntingia calabura L.) dijadikan sampel kering dengan proses pengecilan ukuran dan pengeringan sampel yang bersifat permiabel (mudah ditembus zat cair dan uap). Proses perajangan ini bertujuan agar jaringan tumbuhan dapat terbuka sebanyak mungkin sehingga proses pengeringan dan ekstraksi sampel menjadi lebih cepat (Munawaroh, 2010). Lalu proses ekstraksi menggunakan pelarut etanol.). Etanol dipilih karena memiliki kemampuan melarutkan semua zat dengan cepat, sempurna, serta mempunyai titik didih yang cukup rendah agar pelarut mudah diuapkan tanpa menggunakan suhu tinggi, dan bersifat inert (Munawaroh, 2010). Proses ekstraksi di lanjutkan dengan proses fraksinasi, dibuat fraksi ekstrak kulit batang kersen dengan dua macam pelarut yang berbeda sesuai dengan tingkat kepolarannya yaitu dari pelarut dengan kepolaran rendah sampai pelarut dengan kepolaran lebih tinggi yaitu $n$-heksana dan kemudian etil asetat. Hasil pengekstrasian memiliki rendemen dengan jumlah ekstrak etanol $7,01 \%$, fraksi n-heksan $0,27 \%$, fraksi etil asetat $0,73 \%$, dan fraksi tidak larut 0,69 $\%$ dari ekstrak kasar kulit batang kersen (tabel 1). Hal ini menunjukan bahwa pelarut etanol memiliki kemampuan yang baik untuk dijadikan pelarut dalam ekstraksi kulit batang kersen.

Tabel 1. Rendemen ekstrak kulit batang kersen

\begin{tabular}{cc}
\hline Ekstrak & Rendemen (\%) \\
\hline Ekstrak Kasar & 7,01 \\
Fraksi N-Heksan & 0,27 \\
Fraksi Etil Asetat & 0,73 \\
Fraksi Tidak Larut & 0,69 \\
\hline
\end{tabular}

Senyawa metabolit sekunder adalah produk sekunder dari proses reaksi kimia pada tumbuhan, yang memiliki banyak manfaat contohnya flavonoid sebagai antioksidan. Identifikasi metabolit sekunder pada ekstrak dan fraksi kulit batang kersen memiliki hasil positif pada alkaloid (hanya pada fraksi $n$-heksana), flavonoid, fenolik, tanin, saponin, dan triterpenoid, (tabel 2). Hasil ini sesuai dengan yang telah dilaporkan oleh Arum (2012) dan Prasetyo (2014). 
Tabel 2. Hasil Uji Metabolit Sekunder Ekstrak Kulit Batang Kersen

\begin{tabular}{ccccc}
\hline & $\begin{array}{c}\text { Ekstrak } \\
\text { Kasar }\end{array}$ & $\begin{array}{c}\text { Fraksi N- } \\
\text { Heksan }\end{array}$ & $\begin{array}{c}\text { Fraksi Etil } \\
\text { Asetat }\end{array}$ & $\begin{array}{c}\text { Fraksi Tidak } \\
\text { Larut }\end{array}$ \\
\hline Alkaloid & - & + & - & - \\
Flavonoid & + & - & + & + \\
Fenolik & + & - & + & + \\
Tanin & + & - & + & + \\
Saponin & + & - & - & + \\
Triterpenoid & + & - & & - \\
& (Terpenoid) & & & \\
\hline
\end{tabular}

Keterangan : (+) Positif = Ada Senyawa dan (-) Negatif = Tidak Ada Senyawa

Aktivitas antioksidan ekstrak dan fraksi kulit batang kersen (Muntingia calbaura L.) dilakukan dengan metode DPPH. Nilai IC $_{50}$ dari ekstrak dan fraksi kulit batang kersen disajikan pada Tabel 3. $\mathrm{IC}_{50}$ (Inhibitory Concentration 50) merupakan bilangan yang menunjukan konsentrasi sampel (ppm) yang mampu menghambat radikal bebas sebesar $50 \%$. Semakin kecil nilai $\mathrm{IC}_{50}$ berarti semakin tinggi aktivitas antioksidan. Analisis aktivitas antioksidan sampel ditentukan oleh besarnya serapan radikal DPPH melalui perhitungan persentase penghambatan (inhibisi) serapan DPPH (Kuntorini, 2013).

Aktivitas antioksidan dari ekstrak etanol (Muntingia calabura L.) kulit batang kersen dengan mengunakan konsentrasi pengujian 5 ppm, 10 ppm, 15 ppm, 20 ppm, dan 25 ppm diperoleh IC $_{50}$ 19,632 ppm (Tabel 2). Hasil IC 50 $_{0}$ ekstrak etanol termasuk dalam kategori antioksidan sangat kuat (Putri, 2015). Ekstrak etanol memiliki aktivitas antioksidan karena ekstrak memiliki senyawa metabolit sekunder Flavonoid, Fenolik, Tanin, Saponin, dan Terpenoid.

Aktivitas antioksidan dari fraksi $n$-heksana (Muntingia calabura L.) kulit batang kersen dengan menggunakan konsentrasi pengujian 20 ppm, 30 ppm, 40 ppm, 50 ppm, dan 60 ppm diperoleh hasil $\mathrm{IC}_{50} 34,376$ ppm (Tabel 2). Hasil $\mathrm{IC}_{50}$ fraksi $n$-heksana juga termasuk dalam kategori antioksidan sangat kuat (Putri, 2015). Aktivitas antioksidan fraksi $n$-heksana lebih lemah dari aktivitas antioksidan ekstrak etanol karena kandungan metabolit sekunder fraksi $n$-heksana hanya senyawa alkaloid. 
Tabel 3. Aktivitas antioksidan kulit batang kersen (Muntingia calabura L.)

\begin{tabular}{|c|c|c|c|c|}
\hline Sampel & $\begin{array}{c}\text { Konsentrasi } \\
\text { Uji (ppm) }\end{array}$ & $\begin{array}{l}\text { \% Aktivitas } \\
\text { Antioksidan }\end{array}$ & IC 50 & Keterangan \\
\hline \multirow[t]{5}{*}{ Ekstrak Etanol } & 5 & 10,660 & & \\
\hline & 10 & 26,781 & & \\
\hline & 15 & 38,586 & 19,632 & Sangat Kuat \\
\hline & 20 & 53,406 & & \\
\hline & 25 & 61,310 & & \\
\hline \multirow[t]{5}{*}{ Fraksi $n$-Heksana } & 20 & 28,484 & & \\
\hline & 30 & 45,095 & & \\
\hline & 40 & 58,751 & 34,376 & Sangat Kuat \\
\hline & 50 & 73,969 & & \\
\hline & 60 & 81,828 & & \\
\hline \multirow[t]{5}{*}{ Fraksi Etil Asetat } & 5 & 29,173 & & \\
\hline & 10 & 49,925 & 10,651 & Sangat Kuat \\
\hline & 15 & 67,820 & & \\
\hline & 20 & 79,749 & & \\
\hline & 25 & 83,960 & & \\
\hline Fraksi Etanol & 5 & 11,494 & & \\
\hline \multirow[t]{4}{*}{ (Tidak Larut) } & 10 & 28,391 & & \\
\hline & 15 & 43,046 & 18,703 & Sangat Kuat \\
\hline & 20 & 55,287 & & \\
\hline & 25 & 63,391 & & \\
\hline \multirow[t]{5}{*}{ Vitamin C } & 5 & 15,533 & & \\
\hline & 10 & 33,761 & & \\
\hline & 15 & 51,990 & 14,774 & Sangat Kuat \\
\hline & 20 & 69,063 & & \\
\hline & 25 & 81,772 & & \\
\hline
\end{tabular}

Aktivitas antioksidan dari fraksi etil asetat (Muntingia calabura L.) kulit batang kersen dengan mengunakan konsentrasi pengujian 5 ppm, 10 ppm, 15 ppm, 20 ppm, dan 25 ppm diperoleh $\mathrm{IC}_{50}$ 10,651 ppm (Tabel 2). Hasil $\mathrm{IC}_{50}$ fraksi etil asetat termasuk dalam kategori antioksidan sangat kuat (Putri, 2015). Fraksi etil asetat memiliki aktivitas antioksidan karena fraksi memiliki senyawa metabolit sekunder Flavonoid, Fenolik, dan Tanin. Aktivitas antioksidan fraksi etil asetat lebih kuat dibandingkan dengan aktivitas antioksidan ekstrak etanol karena senyawa metabolit sekunder pada fraksi etil asetat lebih spesifik dibandingkan pada ekstrak etanol.

Aktivitas antioksidan dari fraksi tidak larut (Muntingia calabura L.) kulit batang kersen dengan mengunakan konsentrasi pengujian 5 ppm, 10 ppm, 15 ppm, 
20 ppm, dan 25 ppm diperoleh $\mathrm{IC}_{50} 18,703$ ppm. Hasil $\mathrm{IC}_{50}$ fraksi tidak larut termasuk dalam kategori antioksidan sangat kuat (Putri, 2015). Fraksi tidak larut memiliki aktivitas antioksidan karena ekstrak memiliki senyawa metabolit sekunder Flavonoid, Fenolik, Tanin, dan Saponin.

Potensi aktivitas antioksidan dari ekstrak dan fraksi kulit batang kersen memiliki memiliki potensi yang baik sebagai antioksidan. Bahkan aktivitas antioksidan fraksi etil asetat lebih tinggi dibandingkan dengan kontrol positif yaitu vitamin C dengan $\mathrm{IC}_{50}$ sebesar 14,774 ppm. Hal ini disebabkan karena pada fraksi etil asetat memiliki kandungan metabolit sekunder yang dapat bertindak sebagai senyawa antioksidan seperti Flavanoid (Manik, 2004). Flavonoid adalah suatu antioksidan alam dan mempunyai aktivitas biologis, antara lain sebagai antioksidan yang dapat menghambat berbagai reaksi oksidasi, serta mampu bertindak sebagai pereduksi radikal hidroksil, superoksida dan radikal peroksil.

\section{KESIMPULAN}

1. Ekstrak Dan Fraksi Kulit Batang Kersen (Muntingia calabura L.) memiliki aktivitas antioksidan.

2. Aktivitas Antiosidan Fraksi Etil Asetat lebih baik dari Aktivitas Antioksidan Vitamin C.

\section{DAFTAR PUSTAKA}

Agromedia, Redaksi. 2008. Buku Pintar Tanaman Obat. PT Agromedia pustaka; Jakarta.

Arum, Y.P., Supartono, dan Sudarmin. 2012. Isolasi dan Uji Daya Antimikroba Eksrak Daun Kersen. Jurnal MIPA 35(2); 165-174.

Kuntorini, E.M., Fitriana, S., dan Astuti, M.D., 2013. Struktur Anatomi dan Uji Aktivitas Antioksidan Ekstrak Metanol Daun Kersen (Muntingia calabura L.) Prosiding Semirata FMIPA Universitas Lampung.

Manik, D., Hertiani, T., dan Anshory, H., 2014. Analisis Korelasi Antara Kadar Flavonoid Dengan Aktivitas Antibakteri Ekstrak Etanol dan Fraksi-Fraksi Daun Kersen (Muntingia calabura L.) Terhadap Staphylococcus aureus.Jurnal Khazanah.Vol. 6, No.2.

Munawaroh, S., dan Handayani, P.A., 2010. Ekstraksi Minyak Daun Jeruk Purut (Citrus hystric D.C) dengan Pelarut Etanol dan N-Heksana. Jurnal Kompetensi Teknik. Vol. 2, No. 1.Hal 73-77. 
Prasetyo, A.D., dan Sasongko, H., 2014. Aktivitas Antibakteri Ekstrak Etanol $70 \%$ Daun Kersen (Muntingia calabura L.) terhadap Bacteri Bacillus Subtilis dan Shigella dysentrine sebagai Materi Pembelajaran Biologi SMA Kelas X untuk Mencapai KD 3.4 pada Kurikulum 2013. Jnpemasi-PBIO. Vol. 1, No. 1.Hal 73-77.

Putri, A.A.S., dan Hidayati, N., 2015. Uji Aktivitas Antioksidan Senyawa Fenolik Ekstrak Metanol Kulit Batang Tumbuhan Nyiri Batu (Xylocarpus moluccensis). UNESA Journal of Chemistry Vol. 4, No. 1. 